\title{
Article
}

\section{Can Flaments be stored as a shelf-item for on-demand manufacturing of oral 3D printed tablets? An initial stability assessment}

Okwuosa, Tochukwu Chijioke, Sadia, Muzna, Isreb, Abdullah, Habashy, Rober, Peak, Matthew and Alhnan, Mohamed A

Available at http://clok.uclan.ac.uk/37072/

Okwuosa, Tochukwu Chijioke, Sadia, Muzna, Isreb, Abdullah ORCID: 00000001-9939-6161, Habashy, Rober, Peak, Matthew and Alhnan, Mohamed A (2021) Can Filaments be stored as a shelf-item for on-demand manufacturing of oral 3D printed tablets? An initial stability assessment. International Journal of Pharmaceutics, 600 (12044). ISSN $0378-5173$

It is advisable to refer to the publisher's version if you intend to cite from the work. http://dx.doi.org/10.1016/j.ijpharm.2021.120442

For more information about UCLan's research in this area go to http://www.uclan.ac.uk/researchgroups/ and search for < name of research Group>.

For information about Research generally at UCLan please go to http://www.uclan.ac.uk/research/

All outputs in CLoK are protected by Intellectual Property Rights law, including Copyright law. Copyright, IPR and Moral Rights for the works on this site are retained by the individual authors and/or other copyright owners. Terms and conditions for use of this material are defined in the policies page. 
1 Research paper

2

3 Can Filaments be stored as a shelf-item for on-demand

4 manufacturing of oral 3D printed tablets? An initial stability

5 assessment

6

7

8

9 Tochukwu C Okwuosa ${ }^{1,2}$, Muzna Sadia ${ }^{1}$, Abdullah Isreb $^{1}$, Rober Habashy ${ }^{1}$,

10 Matthew Peak ${ }^{3}$ Mohamed A Alhnan ${ }^{4}$

11

12

13

14

15

16

17

18

19

20

21

22

23

24

25

26

${ }^{1}$ School of Pharmacy and Biomedical Sciences, University of Central Lancashire, Preston PR1 2HE, United Kingdom.

${ }^{2}$ School of Life and Medical Sciences, University of Hertfordshire, AL10 9AB Hatfield, United Kingdom.

${ }^{3}$ Paediatric Medicines Research Unit, Alder Hey Children's NHS Foundation Trust, Liverpool, UK

${ }^{4}$ Institute of Pharmaceutical Science, King's College London, London, United Kingdom.

*Corresponding author at:

Institute of Pharmaceutical Sciences

King's College London

150 Stamford Street

London SE1 9NH. Tel.: +44 (0)20 78487265

Email: Alhnan@kcl.ac.uk 


\section{Abstract}

28 3D printing of oral solid dosage forms is a recently introduced approach for dose personalisation. Fused 29 deposition modelling (FDM) is one of the promising and heavily researched 3D printing techniques. 30 However, the successful application of this technique relies greatly on the mass manufacturing of 31 physically and chemically stable filaments, that can be readily available as a shelf item to be 3D printed on-demand. The stability of methacrylate polymers (Eudragit EPO, RL, L100-55 and S100), hydroxypropyl cellulose-SSL (HPC.SSL) and polyvinyl pyrrolidone (PVP)-based filaments over 6 months were investigated. Filaments manufactured by hot melt extrusion (HME) were stored at either $5{ }^{\circ} \mathrm{C}$ or $30{ }^{\circ} \mathrm{C}+65 \% \mathrm{RH}$ with/without vacuuming. The effects of storage on their dimensions, visual appearance, thermal properties, and 'printability' were analysed. Theophylline content, as well as in vitro release from the $3 \mathrm{D}$ printed tablets were investigated. The filaments were analysed before storage, then after 1, 3 and 6 months from the manufacturing date.

39 Storing filaments at these conditions had a significant effect on their physical properties such as shape, 40 dimensions, flexibility and hence compatibility with FDM 3D printing. The methacrylate-based 41 filaments were more physically stable and more easily printed following storage. Owing to their 42 hygroscopic nature, cellulose- and PVP-based filaments demonstrated a reduction in their glass 43 transition temperature upon storage, leading to increased flexibility and incompatibility with FDM 3D 44 printer. Theophylline contents was not significantly changed during the storage.

45 This work provides preliminary data for the impact of polymer species on the long-term stability of the 46 filaments. In general, storage and packaging conditions have major impact on the potential of on47 demand manufacturing of 3D printed tablets using hot melt extruded filaments. 


\section{Introduction}

For many years, drug dosing for adults were based on the age and weight of the patient, with the dose for children extrapolated linearly from the former. The downside of such an approach is the lack of consideration of demographic, genetic, clinical and environmental factors which have been proven to contribute to population's variabilities (Cella et al. 2010). Hence, varied responses to therapy and susceptibility to adverse drug reactions have always been predominant issues (Al-Metwali and Mulla 2017; Nyboe Andersen et al. 2017). Dose personalisation, therefore, offers the advantage of tailoring doses to the patients' needs when required. With advancements in pharmacogenomics and wearable technologies, there is a rising interest in dose personalisation, in response to tested biomarkers, to achieve target pharmacodynamics and pharmacokinetics profiles.

A readily available dosing system will ensure efficient and safe dosing with minimal adverse effects when administered to patients. However, such an approach is mostly applicable currently for injectables, which allows easy dose adjustments (Patel et al. 2014). For this approach to be widely applied, a digital personalisation solution for commonly used dosage forms e.g. tablets should be developed. Dose adjustments are frequently achieved through the practice of tablet splitting. This approach is reported to introduce dosing inaccuracies (Habib et al. 2014), which could lead to underdosing, overdosing and severe toxicities with certain active pharmaceutical ingredients (APIs).

Different approaches are currently being investigated to personalise oral dosage forms, with 3D printing demonstrating significant potential (Isreb et al. 2019; Pereira et al. 2019; Tagami et al. 2019; Sen et al. 2020; Martinez et al. 2018). FDM has been heavily researched as an effective and accessible 3D printing technique. It offers several advantages such as the absence of a post-printing processing, in addition to its low-cost setup (Pereira et al. 2019; Sadia et al. 2018; Okwuosa et al. 2016). FDM 3D printing involves the use of filaments, usually manufactured by hot melt extrusion, as a pre-product, which are then fed into the heated nozzle of the FDM 3D printer (Pereira et al. 2019; Sadia et al. 2018; Okwuosa et al. 2016; Goyanes et al., 2014).

The potential of FDM 3D printing for on-demand manufacturing relies on producing stable, reproducible, dose-consistent and ready-to-use filaments. In order to effectively utilise this technique, these filaments should be easily mass-produced, packaged and stored before shipping to the printing sites, including hospitals and community pharmacies. This will enable the vision of producing 3D printed dosage forms that are intended to be dispensed shortly after being fabricated to match patients' needs in small batches to be achieved, and should maintain at least the stability standards for extemporaneous preparations. Therefore, the long-term stability of the filament, as a pre-product on the shelves of manufacturing units or compounding pharmacies, is of paramount importance for the success of this approach. 
In the last six years, many studies have focused on the application of FDM 3D printing for dose personalisation (Charoenying et al. 2020; Eleftheriadis et al. 2019; Jamróz et al. 2020; Wei et al. 2020; Zhang et al. 2020; Fanous et al. 2020; Vo et al. 2020; Pereira et al. 2019; Sadia et al. 2018; Okwuosa et al. 2016; Pietrzak et al. 2015). However, there are little to no information about the long-term stability of these filaments. In fact, changes in the physicochemical properties of the filament during storage might not only compromise the efficacy of the active ingredient but may also affect its printability. Hence, adding more complexity to the technical challenges (Ilyés et al. 2019). For instance, a reduced plasticity of the filament upon storage will result in a brittle filament that may often break under pressure from the FDM 3D printer head gears (Ilyés et al. 2019, Nesereddin et al., 2018). Moreover, other changes in the filament diameter and/or shape may also have an impact on the final printed product, leading to variations in 3D printed tablets weights (weight uniformity) and in some cases the failure to complete the 3D printing process (Ilyés et al. 2019).

With many researchers working towards the adaptation of FDM 3D printing in pharmaceutical manufacturing, there is the need to study the stability of commonly used pharmaceutical polymers adapted to suit this novel manufacturing approach. In this work, the stability of HME-based filaments at $5{ }^{\circ} \mathrm{C}$ or $30^{\circ} \mathrm{C}+65 \% \mathrm{RH}$ were investigated. The impacts of the storage and packaging conditions were studied using theophylline as a model drug in combination with different model polymers. As the focus of this work is the impact of storage condition on physical change and the printability of different polymer-based filaments, a chemically stable molecule (Serajuddin, 1986), theophylline was selected as a model drug. The filaments in this study have been previously investigated to achieve immediate and modified release 3D printed structures using commercially available polymers of different chemical nature and hygroscopicity [PVP-based (Okwuosa et al. 2016), HPS.SSL-based (Pietrzak et al. 2015), L100-55-based, S100-based, RL-based and EPO-based filaments (Okwuosa et al. 2017; Sadia et al. 2018; Sadia et al. 2016)]. It is important to highlight that both Eudragit L100-55 and S100-based filaments were used to fabricate the shell in delayed release system and hence were made drug-free. The diameter, printability, thermal properties, physical form of the API, drug content of the filament, and the drug release profile of the 3D printed dosage forms were investigated before and after exposure to the storage conditions. 


\section{Materials and Methods}

\subsection{Materials}

Hydroxypropyl cellulose (HPC.-SSL) was obtained from Nisso Chemical Europe (Dusseldorf, Germany). Theophylline was purchased from ACROS Organics. Polyvinylpyrrolidone (PVP, MW 40,000), triacetin and triethyl citrate (TEC) were purchased from Sigma-Aldrich (UK). Talc was purchased from Fluka Analytical (UK). Eudragit L100-55, RL, EPO and S100 were donated by Evonik Industries (Darmstadt, Germany).

\section{$2.2 \quad$ Preparation of filaments}

The PVP, HPC.-SSL and Eudragit based filaments were produced by HME following previously reported approach (Okwuosa et al. 2016). All filaments contained a model drug (theophylline) except for Eudragit L100-55 and S100 based filaments, which were used to 3D print the enteric layers (Okwuosa et al. 2017). The mixing and processing temperatures of the HME processes and nozzle sizes are detailed in Table 1.

\subsection{Accelerated stability studies (storage conditions)}

In order to determine the stability of the filaments over a long-term storage, accelerated stability studies were carried out according to the International Council for Harmonisation (ICH) guidelines [Q1A(R2)] (ICH, 2003). The drug loaded (PVP, HPC.SSL, Eudragit EPO and RL-based) and the drug free (Eudragit L100-55 and S100-based) filaments were sealed in polyvinyl chloride (PVC) polybags with or without vacuuming and stored in a fridge at $5{ }^{\circ} \mathrm{C}$ or in an incubator at $30{ }^{\circ} \mathrm{C}+65 \% \mathrm{RH}$. Vacuum sealing was achieved using Andrew James VS517 Dom Sealer. The filaments were characterised when freshly prepared and then after 1, 3 and 6 months of storage.

\section{$2.4 \quad$ Filament dimension and visual appearance}

In order to determine the effect of the storage conditions on the diameter of the filaments, changes in the diameter of the filaments were monitored using a Draper Electronic Digital caliper $(0-$ $25 \mathrm{~mm}$ ) with a resolution of $0.001 \mathrm{~mm}$. Filaments were observed to assess change in their visual appearance (change in shape, colour or presence of aggregation).

\subsection{Printability test using FDM $3 D$ printer}

The 3D printing of the filaments that were stored under different conditions was attempted using the parameters detailed in Table 1 to determine the effect of the storage conditions on 3D printing in comparison to a freshly prepared filament using Makerbot Experimental 2X 3D printer (Makerbot Inc, NY, USA). 3D Printing was carried out at a standard resolution ( $0.2 \mathrm{~mm}$ layer thickness) and a 100 $\%$ infill with rectilinear infill pattern. Other settings were set as previously detailed (Okwuosa et al. 
2016). A caplet ( $\mathrm{L} \times \mathrm{W} \times \mathrm{H} 10 \times 4 \times 3.6 \mathrm{~mm}$ ) was designed and imported into the MakerWare software Version 2.4.0.17 (Makerbot Industries, LLC., USA) and used to test the printability of the filaments. The printed caplets weighed approximately $110 \mathrm{mg}$, containing approximately $11,50,50$ and $52 \mathrm{mg}$ of theophylline for the PVP, HPC.SSL, Eudragit RL and EPO-based caplets respectively.

\subsection{Thermal gravimetric analysis (TGA)}

TGA analysis for the extruded filaments was carried out using a TGA Q500 (TA Instruments, Hertfordshire, UK). The filaments were cut into small pieces $(<1 \mathrm{~mm}$, approximately $10 \mathrm{mg})$ were accurately weighed and placed in a $40 \mu \mathrm{L}$ aluminium pan (TA Instruments, Hertfordshire, UK), which was placed on a platinum pan. Samples were then scanned from 25 to $500{ }^{\circ} \mathrm{C}$ at a heating rate of 10 ${ }^{\circ} \mathrm{C} / \mathrm{min}$ with a nitrogen purge of $40 / 60 \mathrm{~mL} / \mathrm{min}$ for the sample and furnace, respectively. All measurements were carried out in triplicates and the data analysed using a TA Universal Analysis 2000 software (TA Instruments, Hertfordshire, UK)

\subsection{Differential scanning calorimetry (DSC)}

For modulated temperature differential scanning calorimetry (MTDSC) analysis, a differential scanning calorimeter (DSC) Q2000 (TA Instruments, Elstree, Hertfordshire, UK) was used. PVP-based filaments were subjected to a modulated heat-cool-heat scan in order to measure and exclude the effect of moisture content on the plasticity of the filaments. Eudragit L100-55 and S100-based filaments were also subjected to a modulated scan. The modulation scan was applied using an amplitude of $0.212{ }^{\circ} \mathrm{C}$ and a period of $40 \mathrm{sec}$, scanning from -70 to $200{ }^{\circ} \mathrm{C}$ at a heating rate of $2{ }^{\circ} \mathrm{C} / \mathrm{min}$.

As moisture did not interfere with the thermographs obtained unlike the aforementioned filaments, a non-modulated standard scan was used for HPC.-SSL, Eudragit RL and EPO-based filaments from -50 to $300{ }^{\circ} \mathrm{C}$ at a heating rate of $10{ }^{\circ} \mathrm{C} / \mathrm{min}$. Analysis was carried out under a purge of nitrogen gas $(50 \mathrm{~mL} / \mathrm{min})$. All the data were analysed using a TA Universal Analysis 2000 software (TA Instruments, Hertfordshire, UK). TA pin-holed standard lids and $40 \mu \mathrm{L}$ aluminium pans (TA Instruments, Hertfordshire, UK) were filled with approximately $5 \mathrm{mg}$ sample and sealed. All measurements were carried out in triplicates.

\subsection{X-ray powder diffractometry (XRPD)}

X-ray powder diffraction was carried out on the filaments over 6 months to investigate changes in the physical forms of the API or excipients. This was assessed using a powder X-ray diffractometer, D2 Phaser with Lynxeye (Bruker, Germany). Filaments were dipped in liquid nitrogen before crushing them using a mortar and pestle. The powders were scanned from 2 Theta $(2 \theta)=5^{\circ}$ to $35^{\circ}$ using 0.01 
step and $1.25 \mathrm{sec}$ count. The divergence slit was $1 \mathrm{~mm}$ and the scatter slit $0.6 \mathrm{~mm}$. The wavelength of the X-ray was $0.154 \mathrm{~nm}$ using $\mathrm{Cu}$ source and a voltage of $30 \mathrm{kV}$ and a current of $10 \mathrm{~mA}$.

\subsection{Determination of drug content (Eudragit EPO, RL, HPC.SSL and PVP-based filaments)}

To determine changes in the drug contents of the filament after storage, $120 \mathrm{mg}$ of the Eudragit EPO and RL, HPC.SSL and PVP-based filaments containing theophylline were solubilised in $0.1 \mathrm{M}$ $\mathrm{HCl}$ and sonicated for $2 \mathrm{~h}$ or $8 \mathrm{~h}$ (for Eudragit RL-based filament only). The API was measured by HPLC using an Agilent UV-HPLC 1260 series (Agilent Technologies, Inc., Germany) and an XTerra RP C18 column $(150 \times 4.6 \mathrm{~mm}, 5 \mu \mathrm{m}$ particle size) (Waters, Ireland). A mobile phase of $10 \mathrm{mM}$ solution of ammonium acetate buffer, methanol and acetonitrile at volume ratio of 86:7:7. Analysis was carried out at a wavelength of $272 \mathrm{~nm}$, column temperature of $40{ }^{\circ} \mathrm{C}$, flow rate of $1 \mathrm{~mL} / \mathrm{min}$, injection volume was $5 \mu \mathrm{L}$ and a run time of $7 \mathrm{~min}$ as reported previously (Okwuosa et al. 2016).

\subsection{In vitro drug release studies (Eudragit EPO and RL-based filament)}

In vitro drug release studies for the 3D printed tablets were carried out using a USP II dissolution apparatus (AT 7 Smart, Sotax, Switzerland). The tablets were tested in $900 \mathrm{~mL}$ of $0.1 \mathrm{M}$ $\mathrm{HCl}$ solution for the EPO-based tablets for 2 hours. However, for the extended release formulation (Eudragit RL), dissolution testing was carried out in $750 \mathrm{~mL}$ of $\mathrm{HCl}$ solution, followed by the addition of $250 \mathrm{~mL}$ of $0.215 \mathrm{M}$ tribasic phosphate buffer after $2 \mathrm{hrs}$ and the $\mathrm{pH}$ adjusted to 6.8. Samples were collected for another $6 \mathrm{hrs}$. The samples were automatically collected and analysed at 5 min intervals using a UV/VIS spectrophotometer (PG instruments limited, UK) at a wavelength of $272 \mathrm{~nm}$. The path length used was $1 \mathrm{~mm}$. The data were analysed using IDIS Software version 2.0 Automated Lab (Berkshire, UK).

\section{$2.11 \quad$ Statistical analysis}

One-way ANOVA was employed using SPSS Software (22.0.0.2) to analyse the results. the level of statistical significance was set at $(\mathrm{p}<0.05)$. 


\section{Results and discussions}

The use of FDM 3D printing for on-demand dose personalisation relies greatly on the manufacturing of stable filaments that will be able to withstand storage and transportation. This ensures compatibility with the FDM 3D printer at the point of use, whilst maintaining the integrity of the loaded APIs and meeting the individual needs of patients. Therefore, the goal of this research was to investigate stability-related challenges that could be faced in the use of methacrylate, cellulose and polyvinyl pyrrolidone-based filaments for FDM 3D printing.

\subsection{Physical and thermal properties of the stored filaments}

Changes in the physical and thermal properties of these filaments due to storage could affect their 3D printing into solid dosage forms. Therefore, the impact of the storage conditions on the diameter of the filaments were investigated. It was observed that a filament diameter $>1.8 \mathrm{~mm}$ will lead to blockage due to its inability to pass through the liquifying chamber of the FDM 3D printer's head. This is an essential quality criterion of the filaments to ensure consistent flow through the pressing gears into the hot nozzle. In addition, deformations in the cylindrical shape of the filament (deviation from the cylindrical shape) could potentially affect the filament interaction with the gears in the 3D printer, leading to inconsistency of the flow through the hot nozzle. Such effect can result in weight variation of the 3D printed product (data not included). These changes could also be influenced by the changes in the thermal properties of the filaments, with the TGA analysis being able to investigate water gain or loss and changes in the degradation profile of the stored filaments, with reference to the freshly prepared samples. Also, changes in the glass transition temperature $(\mathrm{Tg})$ of the filament can significantly alter the mechanical properties of the filaments, in turn, the ability to load the filaments into the liquifying chamber of the FDM 3D printer head. Therefore, investigations into the effect of the storage conditions on the $\mathrm{Tg}$ of the filaments were also carried out using thermal method.

\section{a) Methacrylate-based filaments}

Investigating the diameter of Eudragit EPO-based filaments after storage revealed that no change was noted when stored at $5{ }^{\circ} \mathrm{C}$. However, storing the filaments at $30{ }^{\circ} \mathrm{C}+65 \% \mathrm{RH}$ resulted in a permanent flattening/deformation of these filaments only when the storage bag was vacuum-sealed (Table 2). The resultant deformation_affected its compatibility with the 3D printer and prevented its conversion into a solid dosage form. The TGA analysis of this filament demonstrated similar thermographs in the storage conditions (Fig. 1A) in comparison to a freshly prepared sample with insignificant moisture uptake with no observed wright loss between $50-150{ }^{\circ} \mathrm{C}$, a usual indication of water evaporation due to hygroscopicity. This non-hygroscopic nature of this polymer was also observed by Parikh et al. (2014) who recorded a $0.2 \%$ w/w moisture content. On the other hand, the DSC analysis revealed a slight reduction in the Tg of the filament due to storage (Fig. 1B). However, 
this did not affect the printability of the filaments stored at $5{ }^{\circ} \mathrm{C}$ and $30{ }^{\circ} \mathrm{C}$ with no vacuuming. The flattening of the vacuum-sealed filament when stored at $30{ }^{\circ} \mathrm{C}$ could be attributed to the increased mobility of the polymeric chains above the Tg of the Eudragit EPO matrix. In addition, the negative pressure on the filaments due to the vacuuming, may have also contributed to the deformation of the filament. This was confirmed when a protective shell placed around the filaments, resulted in no alteration in shape at the same storage conditions (data not included).

The Eudragit RL-based filament also lost its original cylindrical shape when stored in a vacuumed PVC bag at $30{ }^{\circ} \mathrm{C}$ and $65 \% \mathrm{RH}$, and hence was incompatible with the FDM 3D printer only at this storage condition (Table 2). This was also the case for Eudragit L100-55--based filaments. Both Eudragit based filaments demonstrated no changes in their weight loss TGA patterns due to storage as well as no indication of water uptake (Figs. $2 \mathrm{~A}$ and 3A). The filaments stored at $5{ }^{\circ} \mathrm{C}$ (with or without vacuuming) and in a non-vacuumed bag at $30{ }^{\circ} \mathrm{C}+65 \% \mathrm{RH}$ were easily printed, demonstrating desirable filament properties. An increase in Tg was observed, however, this had no effect on the filament's printability (Figs. 2B and 3B) (Melocchi et al. 2020).

The dimensions of Eudragit S100-based filaments did not incur any significant changes due to storage and maintained compatibility with the FDM 3D printer, irrespective of the storage condition (Table 2). Their TGA thermographs remained similar during storage, demonstrating no water uptake during the storage period (Fig. 4A). Unlike the previously discussed filaments, the S100-based filaments demonstrated a higher $\mathrm{Tg}$ value $\left(85-89^{\circ} \mathrm{C}\right)(\mathbf{F i g} . \mathbf{4 B})$, hence were unaffected by the storage at $30^{\circ} \mathrm{C}$ and the vacuuming pressure.

\section{b) Hydroxypropyl cellulose-based filaments}

The HPC-based filament deformed when stored in a vacuumed bag at $30{ }^{\circ} \mathrm{C}$ and $65 \% \mathrm{RH}$. In addition, the filaments from other storage conditions were also incompatible with the FDM 3D printer. The TGA analysis of the stored filaments showed weight gain values of $2.25 \%$ and $2 \% \mathrm{w} / \mathrm{w}$ for filaments stored at 5 and $30{ }^{\circ} \mathrm{C}+65 \% \mathrm{RH}$, respectively (Fig. 5A). This demonstrated the hygroscopic nature of the cellulose-based matrix (Rowe et al. 2006). Water has often been reported to have a plasticising effect on polymeric matrices (Teng et al. 2010), leading to a drop in the $\mathrm{Tg}$ of these filaments from 36.7 to $34.9{ }^{\circ} \mathrm{C}$ after storage as demonstrated by DSC thermograph (Fig. 5B). This confirms the potential role of water uptake as a major disruptor for compatibility with FDM 3D printing process, due to increased flexibility. Such an increase will obstruct feeding into the liquifying chamber of the FDM head, resulting in a poor grip of the gears on the filament and subsequently, the folding of the filaments around the gears (Ilyés et al. 2019). This effect of high plasticity on the printability of the filaments was also observed by Tan et al. (2020). As a result of these initial negative findings following one-month storage, the HPC-based filaments were withdrawn from further studies. 
Investigating the physical properties of the PVP-based filaments revealed their stability only at the $5{ }^{\circ} \mathrm{C}$ storage condition where they retained their shape and diameter. The TGA of freshly prepared PVPbased filaments depicted an initial weight loss of approximately $4 \%$ at around $120{ }_{-}^{\circ} \mathrm{C}$ due to moisture loss, which could be attributed to the hygroscopic nature of PVP (Gupta et al. 2014). The storage of the filaments at $5{ }^{\circ} \mathrm{C}$ resulted in up to $6.5 \%$ water uptake (Fig. 6). PVP has been reported to be able to take moisture up to $40 \%$ of its weight (Ramineni et al. 2013). It was not possible to determine precisely the $\mathrm{Tg}$ of these filaments due to the excessive water evaporation upon heating ${ }_{2}$-which interfered with the detectability of the polymer's Tg. A heat-cool-heat DSC approach could eliminate these effects of moisture. However, this approach led to the removal of moisture during the first heat scan and can mask the potential of storage on Tg of the filament (Supplementary Data, Fig. S1 and S2). Such high wateruptake was reported to produce a significant drop in its Tg (Fitzpatrick et al. 2002; Xie and Taylor 2017; Teng et al. 2010). Although the filaments at $5{ }^{\circ} \mathrm{C}$ remained compatible with the $3 \mathrm{D}$ printer, their very hygroscopic nature poses a major challenge to their application. Therefore, a future product would require the use a specific packaging for these filaments to provide moisture-controlled environment. This might have major implications on the cost and practicality of using these filaments for on-demand use in the community and hospital pharmacies.

\subsection{Impact of storage conditions on the physical form of theophylline}

Changes in the physical forms of theophylline and excipients due to storage can influence the drug release profile. Due to the degradation of methacrylate polymers when thermally scanned $>170$ (melting point of $272{ }^{\circ} \mathrm{C}$ ) To investigate this, XRPD was used to analyse the filaments before and after storage. The Eudragit EPO, RL, HPC.SSL and PVP-based filaments loaded with theophylline revealed the presence of diffraction peaks at $(2 \theta)=7$ and $12^{\circ}$ (Fig. 7), which corresponds to theophylline crystals. Talc, which was used as the structure forming agent, demonstrated sharp peaks at $(2 \theta)=9.52,19.54$, $28.87^{\circ}$. The drug peaks indicated that a proportion of the API remained crystalline within the filament, following thermal and mechanical stress of the HME processes (Huang and Dai 2014). This proved to be dependent on the model drugs as previously investigated using these matrices (Okwuosa et al. 2016; Sadia et al. 2016). The intensity peaks that corresponds to theophylline were also observed after storage, indicating that a proportion of the API is in its crystalline form during these storage conditions. However, the peak intensity at $(2 \theta)=12^{\circ}$ due to theophylline was observed to increase for Eudragit EPO-based filament whilst it decreased for the Eudragit RL-based filament over time (Figs. 7A and

311 B). Variations in peak intensity has been linked to crystalline concentrations (Siddiqui et al. 2015). 312 Also, it was reported that partial crystalline nature of matrices could alter due to storage (Lust et al. 313 2015; Huang and Dai 2014; Ueda et al. 2020). For filaments that did not include drug (Eudragit L100- 
55 and S100), there were diffraction peaks at $(2 \theta)=9.52,19.54,28.87$, which corresponds to the crystals

315 of talc, throughout the storage (Supplementary Data, Figs. S3, S4, S5 and S6).

\section{$316 \quad 3.3 \quad$ Drug integrity and in vitro drug release}

It was important that the integrity of the API-loaded in the filaments (Eudragit EPO, RL, HPC and PVP-based) remains intact throughout the stability trial. This was important to ensure dosing accuracy towards meeting the individual needs of patients using this novel manufacturing approach. HPLC analysis showed no significant changes in API contents (Supplementary Data, Table S1), confirming the stability of theophylline in the matrix.

Cellulose and the PVP-based filaments were deemed unstable and the L100-55 and S100-based filaments were drugs-free, therefore, the dissolution testing for the tablets printed from these filaments was not investigated. In vitro release study on the PVP-based matrices using USP II dissolution apparatus demonstrated an increase in the rate of drug release with the aging of the filament (Fig. 8), which was not as expected (Tian et al. 2014). The highly hygroscopic nature of PVP led to an increase in moisture contents within the polymeric matrix. Drug mobility may also increase leading to phase separation and further drug crystallisation (Chen et al. 2018).

Eudragit EPO is an immediate release polymer and as expected, the caplets from a freshly prepared filament achieved more than $75 \%$ theophylline release at $45 \mathrm{~min}$. However, the rate of release slowed down over time due to storage at 5 and $30{ }^{\circ} \mathrm{C}+65 \% \mathrm{RH}$ (Fig. 9). This could be due to crystalline growth during storage at high temperature and humidity (Tian et al. 2014). This was observed in the XRPD analysis of the filament with peak intensity due to theophylline increasing as the filament ages. It is also possible that during storage, polymer relaxation led to the formation of denser matrix, leading to reduced dissolution rate. Phase separation was observed in a solid dispersion of indometacin and Eudragit EPO produced by HME, which decreased the dissolution rate of the active (Sarode et al. 2013).

On the other hand, Eudragit RL-based tablets showed a faster drug release after storage at $5{ }^{\circ} \mathrm{C}$ in comparison to the fresh sample (Fig. 10). A depression in peak intensity with aging was observed from the XRPD studies, suggesting that more of the active became dissolved in the polymer over time. Filaments stored at $30{ }^{\circ} \mathrm{C}$ did not show a significant change in drug release compared to a freshly prepared product. A solid dispersion containing Eudragit RL and indometacin demonstrated no alteration in drug release after exposure to $40^{\circ} \mathrm{C}$ and $50^{\circ} \mathrm{C}$ for a short period of time $(5 \mathrm{~h}$ ) (Azarmi et al. 2002). 


\section{Conclusions}

347 This work highlights some of the stability challenges facing HME based-filaments as a pre-product 348 shelf item for on-demand use via FDM 3D printing. Storage conditions had a major impact on the 349 physical properties of the filaments such as shape, dimensions, flexibility and hence compatibility with 350 the FDM 3D printing. In comparison to the cellulose- and povidone-based filaments, methacrylatebased filaments (Eudragit EPO, RL, S100 and L100-55) were more generally physically stable and

352 continued to be printable following storage. Polymers of lower Tg required specific storage conditions 353 such as the use of a vacuumed container or fridge temperature. Filaments based on hygroscopic 354 polymers (HPC and PVP) were more sensitive to Tg alterations due to water uptake, leading to 3D 355 printing failures, and hence they were deemed less suitable to be used as a shelf-item product for on356 demand printing. Overall, the integrity of the API in the drug loaded filaments was maintained.

357 This research provides a pioneering preview on the long-term stability consideration of pharmaceutical 358 filaments. Further research is needed to confirm this trend with a wider range of polymers and to asses 359 the impact of filament storage on the conforming of produced table batches with compendial criteria. 360 For FDM 3D printing to be successfully adopted for on-demand manufacturing, more research on this important area is required. 


\section{References}

Al-Metwali, B., and H. Mulla. 2017. "Personalised dosing of medicines for children." J Pharm Pharmacol 69 (5): 514-524. https://doi.org/10.1111/jphp.12709.

Azarmi, S., J. Farid, A. Nokhodchi, S. M. Bahari-Saravi, and H. Valizadeh. 2002. "Thermal treating as a tool for sustained release of indomethacin from Eudragit RS and RL matrices." International Journal of Pharmaceutics 246 (1): 171-177. https://doi.org/https://doi.org/10.1016/S03785173(02)00378-2.

Cella, Massimo, Catherijne Knibbe, Meindert Danhof, and Oscar Della Pasqua. 2010. "What is the right dose for children?" British journal of clinical pharmacology 70 (4): 597-603. https://doi.org/10.1111/j.1365-2125.2009.03591.x.

Charoenying, Thapakorn, Prasopchai Patrojanasophon, Tanasait Ngawhirunpat, Theerasak Rojanarata, Prasert Akkaramongkolporn, and Praneet Opanasopit. 2020. "Three-dimensional (3D)-printed devices composed of hydrophilic cap and hydrophobic body for improving buoyancy and gastric retention of domperidone tablets." European Journal of Pharmaceutical Sciences 155: 105555. https://doi.org/https://doi.org/10.1016/j.ejps.2020.105555.

Chen, Huijun, Yipshu Pui, Chengyu Liu, Zhen Chen, Ching-Chiang Su, Michael Hageman, Munir Hussain, Roy Haskell, Kevin Stefanski, Kimberly Foster, Olafur Gudmundsson, and Feng Qian. 2018. "Moisture-Induced Amorphous Phase Separation of Amorphous Solid Dispersions: Molecular Mechanism, Microstructure, and Its Impact on Dissolution Performance." Journal of $\begin{array}{lllll}\text { Pharmaceutical } & \text { Sciences } & 107 & \text { 317-326. }\end{array}$ https://doi.org/https://doi.org/10.1016/j.xphs.2017.10.028.

Eleftheriadis, Georgios K., Christos Ritzoulis, Nikolaos Bouropoulos, Dimitrios Tzetzis, Dimitrios A. Andreadis, Johan Boetker, Jukka Rantanen, and Dimitrios G. Fatouros. 2019. "Unidirectional drug release from 3D printed mucoadhesive buccal films using FDM technology: In vitro and ex vivo evaluation." European Journal of Pharmaceutics and Biopharmaceutics 144: 180-192. https://doi.org/https://doi.org/10.1016/j.ejpb.2019.09.018.

Fanous, Marina, Sarah Gold, Stefan Hirsch, Joerg Ogorka, and Georgios Imanidis. 2020. "Development of immediate release (IR) 3D-printed oral dosage forms with focus on industrial relevance." European Journal of Pharmaceutical Sciences 155: 105558. https://doi.org/https://doi.org/10.1016/j.ejps.2020.105558.

Fitzpatrick, Shaun, James F. McCabe, Catherine R. Petts, and Steven W. Booth. 2002. "Effect of moisture on polyvinylpyrrolidone in accelerated stability testing." International Journal of Pharmaceutics 246 (1): 143-151. https://doi.org/https://doi.org/10.1016/s03785173(02)00375-7. http://www.sciencedirect.com/science/article/pii/S0378517302003757.

Goyanes, A., Buanz, A.B., Basit, A.W., Gaisford, S., 2014. Fused-filament 3D printing (3DP) for fabrication of tablets. International journal of pharmaceutics $476,88-92$.

Gupta, Simerdeep Singh, Anuprabha Meena, Tapan Parikh, and Abu T.M. Serajuddin. 2014. Investigation of thermal and viscoelastic properties of polymers relevant to hot melt extrusion - I: Polyvinylpyrrolidone and related polymers. Vol. 5.

Habib, W. A., A. S. Alanizi, M. M. Abdelhamid, and F. K. Alanizi. 2014. "Accuracy of tablet splitting: Comparison study between hand splitting and tablet cutter." Saudi Pharm J 22 (5): 454-9. https://doi.org/10.1016/j.jsps.2013.12.014.

Huang, Yanbin, and Wei-Guo Dai. 2014. "Fundamental aspects of solid dispersion technology for poorly soluble drugs." Acta Pharmaceutica Sinica $B \quad 4 \quad$ (1): 18-25. https://doi.org/https://doi.org/10.1016/j.apsb.2013.11.001.

Ilyés, Kinga, Norbert Krisztián Kovács, Attila Balogh, Enikő Borbás, Balázs Farkas, Tibor Casian, György Marosi, Ioan Tomuță, and Zsombor Kristóf Nagy. 2019. "The applicability of pharmaceutical polymeric blends for the fused deposition modelling (FDM) 3D technique: Material considerations-printability-process modulation, with consecutive effects on in vitro release, 
stability and degradation." European Journal of Pharmaceutical Sciences 129: 110-123. https://doi.org/https://doi.org/10.1016/j.ejps.2018.12.019.

ICH Harmonised Tripartite Guideline. 2003. "Stability Testing of New Drug Substances and Products Q1A(R2)."Accessed

31/12. https://database.ich.org/sites/default/files/Q1A\%28R2\%29\%20Guideline.pdf.

Isreb, A., K. Baj, M. Wojsz, M. Isreb, M. Peak, and M. A. Alhnan. 2019. "3D printed oral theophylline doses with innovative 'radiator-like' design: Impact of polyethylene oxide (PEO) molecular weight." Int J Pharm 564: 98-105. https://doi.org/10.1016/j.ijpharm.2019.04.017.

Jamróz, Witold, Mateusz Kurek, Joanna Szafraniec-Szczęsny, Anna Czech, Karolina Gawlak, Justyna Knapik-Kowalczuk, Bartosz Leszczyński, Andrzej Wróbel, Marian Paluch, and Renata Jachowicz. 2020. "Speed it up, slow it down...An issue of bicalutamide release from 3D printed tablets." European Journal of Pharmaceutical Sciences 143: 105169. https://doi.org/https://doi.org/10.1016/j.ejps.2019.105169.

Lust, Andres, Clare J. Strachan, Peep Veski, Jaakko Aaltonen, Jyrki Heinämäki, Jouko Yliruusi, and Karin Kogermann. 2015. "Amorphous solid dispersions of piroxicam and Soluplus ${ }^{\circledR}$ : Qualitative and quantitative analysis of piroxicam recrystallization during storage." International Journal of $\begin{array}{lll}\text { Pharmaceutics } & 486 & (1):\end{array}$ https://doi.org/https://doi.org/10.1016/j.ijpharm.2015.03.079.

Martinez, P. R., A. Goyanes, A. W. Basit, and S. Gaisford. 2018. "Influence of Geometry on the Drug Release Profiles of Stereolithographic (SLA) 3D-Printed Tablets." AAPS PharmSciTech 19 (8): 3355-3361. https://doi.org/10.1208/s12249-018-1075-3.

Melocchi, Alice, Marco Uboldi, Alessandra Maroni, Anastasia Foppoli, Luca Palugan, Lucia Zema, and Andrea Gazzaniga. 2020. "3D printing by fused deposition modeling of single- and multicompartment hollow systems for oral delivery - A review." International Journal of Pharmaceutics 579: 119155. https://doi.org/https://doi.org/10.1016/j.ijpharm.2020.119155.

Nasereddin, J.M., Wellner, N., Alhijjaj, M., Belton, P., Qi, S., 2018. Development of a Simple Mechanical Screening Method for Predicting the Feedability of a Pharmaceutical FDM 3D Printing Filament. Pharm Res 35, 151.

Nyboe Andersen, A., S. M. Nelson, B. C. Fauser, J. A. García-Velasco, B. M. Klein, and J. C. Arce. 2017. "Individualized versus conventional ovarian stimulation for in vitro fertilization: a multicenter, randomized, controlled, assessor-blinded, phase 3 noninferiority trial." Fertil Steril 107 (2): 387-396.e4. https://doi.org/10.1016/j.fertnstert.2016.10.033.

Okwuosa, T.C., Pereira, B.C., Arafat, B., Cieszynska, M., Isreb, A., Alhnan, M.A., 2017. Fabricating a Shell-Core Delayed Release Tablet Using Dual FDM 3D Printing for Patient-Centred Therapy. Pharm Res 34, 427-437.

Okwuosa, Tochukwu C., Dominika Stefaniak, Basel Arafat, Abdullah Isreb, Ka-Wai Wan, and Mohamed A. Alhnan. 2016. "A Lower Temperature FDM 3D Printing for the Manufacture of PatientSpecific Immediate Release Tablets." Pharmaceutical Research 33 (11): 2704-2712. https://doi.org/10.1007/s11095-016-1995-0. http://dx.doi.org/10.1007/s11095-016-1995-0.

Parikh, Tapan, Simerdeep Singh Gupta, Anuprabha Meena, and Abu Serajuddin. 2014. "Investigation of thermal and viscoelastic properties of polymers relevant to hot melt extrusion - III: Polymethacrylates and polymethacrylic acid based polymers." Journal of Excipients and Food Chemicals 5: 56-64.

Patel, J. N., B. H. O'Neil, A. M. Deal, J. G. Ibrahim, G. B. Sherrill, O. A. Olajide, P. M. Atluri, J. J. Inzerillo, C. H. Chay, H. L. McLeod, and C. M. Walko. 2014. "A community-based multicenter trial of pharmacokinetically guided 5-fluorouracil dosing for personalized colorectal cancer therapy." Oncologist 19 (9): 959-65. https://doi.org/10.1634/theoncologist.2014-0132.

Pereira, B. C., A. Isreb, R. T. Forbes, F. Dores, R. Habashy, J. B. Petit, M. A. Alhnan, and E. F. Oga. 2019. "'Temporary Plasticiser': A novel solution to fabricate 3D printed patient-centred cardiovascular 'Polypill' architectures." Eur J Pharm Biopharm 135: 94-103. https://doi.org/10.1016/j.ejpb.2018.12.009. 
Pietrzak, K., A. Isreb, and M. A. Alhnan. 2015. "A flexible-dose dispenser for immediate and extended release 3D printed tablets." Eur J Pharm Biopharm 96: 380-7. https://doi.org/10.1016/j.ejpb.2015.07.027.

Ramineni, Sandeep K., Larry L. Cunningham, Thomas D. Dziubla, and David A. Puleo. 2013. "COMPETING PROPERTIES OF MUCOADHESIVE FILMS DESIGNED FOR LOCALIZED DELIVERY OF IMIQUIMOD." Biomaterials science 1 (7): 753-762. https://doi.org/10.1039/C3BM60064E.

Rowe, Raymond C., Paul J. Sheskey, and Siân C. Owen. 2006. Handbook of pharmaceutical excipients. 5th ed. Vol. Book, Whole. London: Pharmaceutical Press.

Sadia, M., A. Isreb, I. Abbadi, M. Isreb, D. Aziz, A. Selo, P. Timmins, and M. A. Alhnan. 2018. "From 'fixed dose combinations' to 'a dynamic dose combiner': 3D printed bi-layer antihypertensive tablets." Eur J Pharm Sci 123: 484-494. https://doi.org/10.1016/j.ejps.2018.07.045.

Sadia, M., A. Sosnicka, B. Arafat, A. Isreb, W. Ahmed, A. Kelarakis, and M. A. Alhnan. 2016. "Adaptation of pharmaceutical excipients to FDM 3D printing for the fabrication of patient-tailored immediate release tablets." Int J Pharm 513 (1-2): 659-668. https://doi.org/10.1016/j.ijpharm.2016.09.050.

Sarode, Ashish L., Harpreet Sandhu, Navnit Shah, Waseem Malick, and Hossein Zia. 2013. "Hot Melt Extrusion for Amorphous Solid Dispersions: Temperature and Moisture Activated DrugPolymer Interactions for Enhanced Stability." Molecular Pharmaceutics 10 (10): 3665-3675. https://doi.org/10.1021/mp400165b. https://doi.org/10.1021/mp400165b.

Sen, Koyel, Arushi Manchanda, Tanu Mehta, Anson W. K. Ma, and Bodhisattwa Chaudhuri. 2020. "Formulation design for inkjet-based 3D printed tablets." International Journal of Pharmaceutics 584: 119430. https://doi.org/https://doi.org/10.1016/j.ijpharm.2020.119430.

Serajuddin, A.T., 1986. Comparative thermal properties of the monohydrates of sodium theophylline and theophylline. J Pharm Pharmacol 38, 93-96.

Siddiqui, A., Z. Rahman, M. Korang-Yeboah, and M. A. Khan. 2015. "Development and validation of Xray diffraction method for quantitative determination of crystallinity in warfarin sodium products." Int J Pharm 493 (1-2): 1-6. https://doi.org/10.1016/j.ijpharm.2015.07.051.

Tagami, T., M. Ando, N. Nagata, E. Goto, N. Yoshimura, T. Takeuchi, T. Noda, and T. Ozeki. 2019. "Fabrication of Naftopidil-Loaded Tablets Using a Semisolid Extrusion-Type 3D Printer and the Characteristics of the Printed Hydrogel and Resulting Tablets." J Pharm Sci 108 (2): 907-913. https://doi.org/10.1016/j.xphs.2018.08.026.

Tan, D. K., M. Maniruzzaman, and A. Nokhodchi. 2020. "Development and Optimisation of Novel Polymeric Compositions for Sustained Release Theophylline Caplets (PrintCap) via FDM 3D Printing." Polymers (Basel) 12 (1). https://doi.org/10.3390/polym12010027.

Teng, Jing, Simon Bates, David A. Engers, Kevin Leach, Paul Schields, and Yonglai Yang. 2010. "Effect of Water Vapor Sorption on Local Structure of Poly(vinylpyrrolidone)." Journal of $\begin{array}{lllll}\text { Pharmaceutical } & \text { Sciences } & 99 & \text { 3): }\end{array}$ https://doi.org/https://doi.org/10.1002/jps.22204.

Tian, Bin, Ling Zhang, Zhendong Pan, Jingxin Gou, Yu Zhang, and Xing Tang. 2014. "A comparison of the effect of temperature and moisture on the solid dispersions: Aging and crystallization." International Journal of Pharmaceutics $475 \quad$ (1): $385-392$. https://doi.org/https://doi.org/10.1016/j.ijpharm.2014.09.010.

Ueda, Keisuke, Hitomi Okada, Zhijing Zhao, Kenjirou Higashi, and Kunikazu Moribe. 2020. "Application of solid-state $13 \mathrm{C}$ relaxation time to prediction of the recrystallization inhibition strength of polymers on amorphous felodipine at low polymer loading." International Journal of Pharmaceutics 581: 119300. https://doi.org/https://doi.org/10.1016/j.ijpharm.2020.119300.

Vo, Anh Q., Jiaxiang Zhang, Dinesh Nyavanandi, Suresh Bandari, and Michael A. Repka. 2020. "Hot melt extrusion paired fused deposition modeling 3D printing to develop hydroxypropyl cellulose based floating tablets of cinnarizine." Carbohydrate Polymers 246: 116519. https://doi.org/https://doi.org/10.1016/j.carbpol.2020.116519. 
Wei, Can, Nayan G. Solanki, Jaydip M. Vasoya, Ankita V. Shah, and Abu T. M. Serajuddin. 2020. "Development of 3D Printed Tablets by Fused Deposition Modeling Using Polyvinyl Alcohol as Polymeric Matrix for Rapid Drug Release." Journal of Pharmaceutical Sciences 109 (4): 15581572. https://doi.org/https://doi.org/10.1016/j.xphs.2020.01.015.

Xie, Tian, and Lynne S. Taylor. 2017. "Effect of Temperature and Moisture on the Physical Stability of Binary and Ternary Amorphous Solid Dispersions of Celecoxib." Journal of Pharmaceutical Sciences 106 (1): 100-110. https://doi.org/https://doi.org/10.1016/j.xphs.2016.06.017.

Zhang, Jiaxiang, Rishi Thakkar, Yu Zhang, and Mohammed Maniruzzaman. 2020. "Structure-Function Correlation and Personalized 3D Printed Tablets using a Quality by Design (QbD) Approach." International Journal of 119945. https://doi.org/https://doi.org/10.1016/j.ijpharm.2020.119945. 

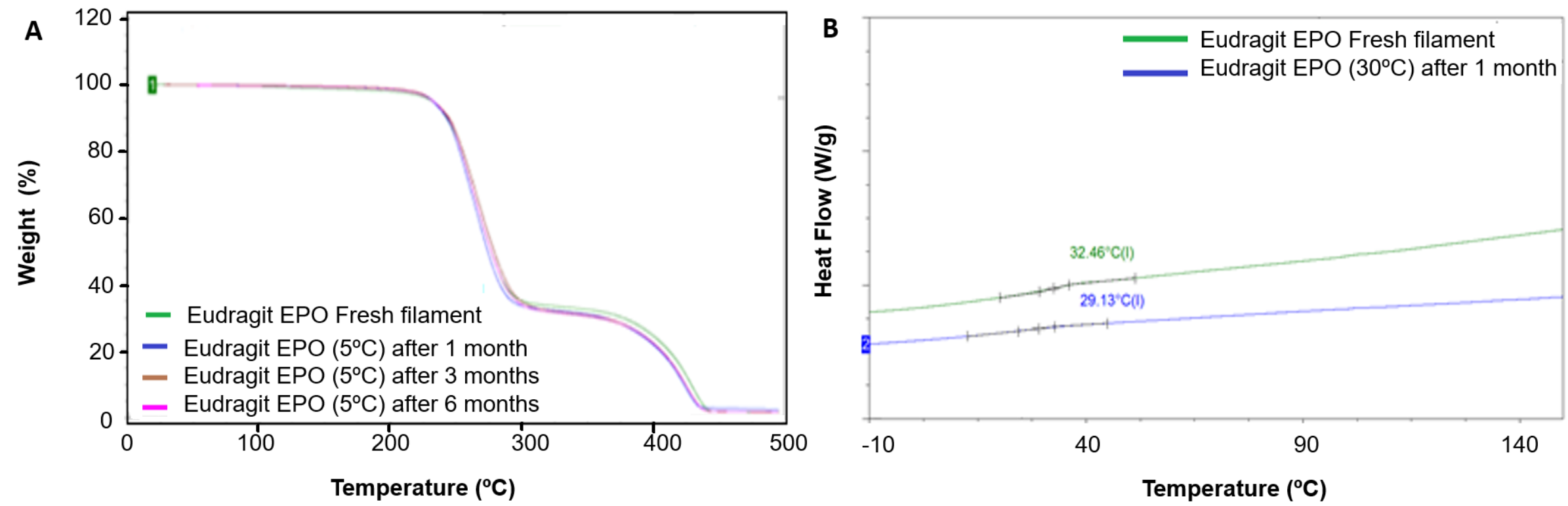

Fig. 1. TGA (A) thermographs for the impact of the storage condition $\left(5^{\circ} \mathrm{C}\right)$ on Eudragit EPO-based filament., (B) DSC thermographs for the impact of the storage condition $\left(30^{\circ} \mathrm{C}\right.$ ) on Eudragit EPO-based filament (filaments deformed and no further assessment was carried out after 1 month. 

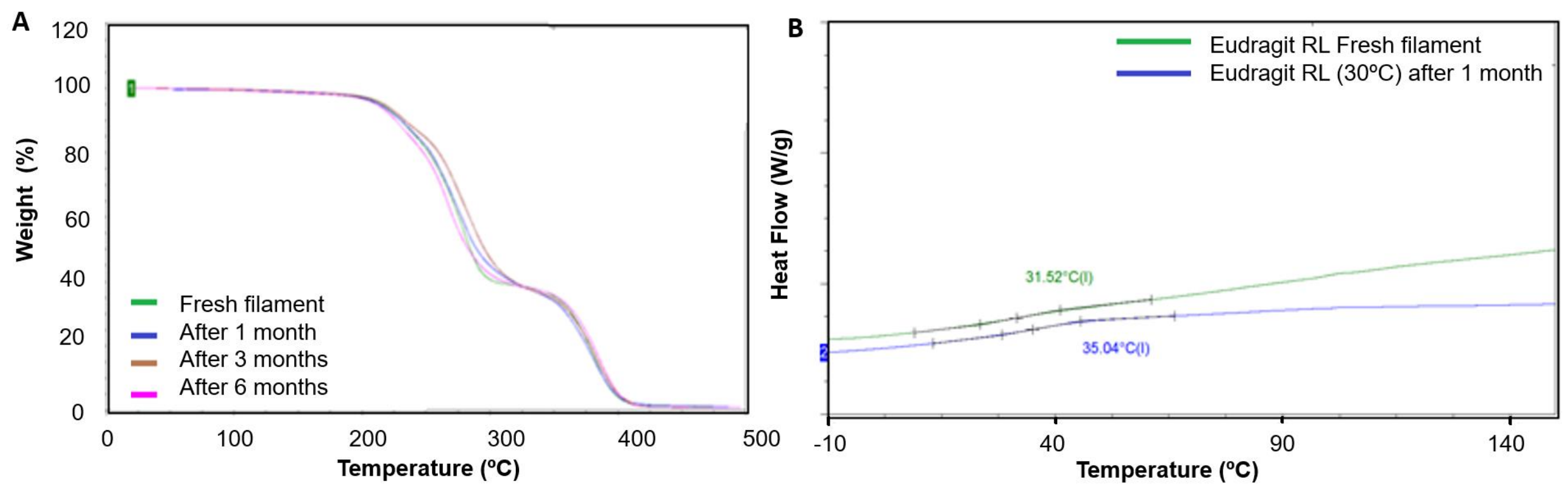

Fig. 2. TGA (A) and DSC (B) thermographs for the impact of the storage conditions on the Eudragit RL-based filament. 
A

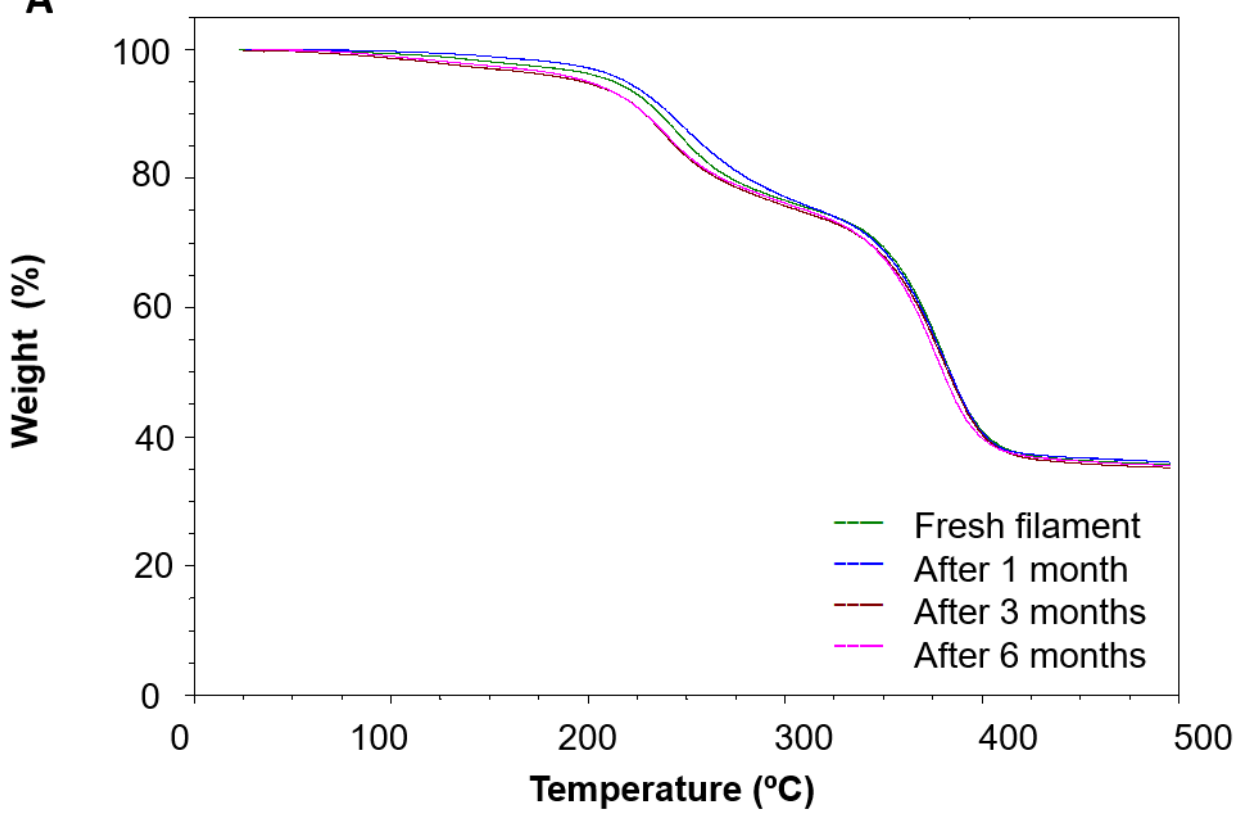

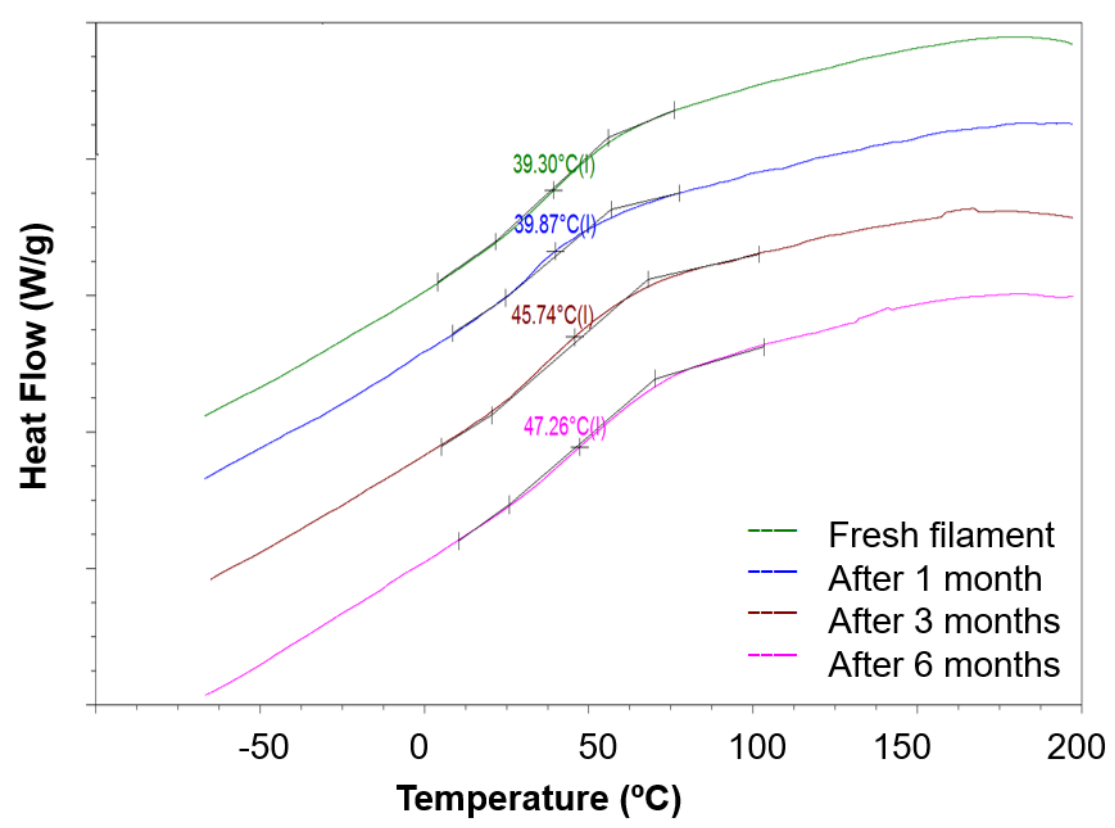

Fig. 3. TGA (A) and DSC (B) thermographs for the impact of the storage conditions ( $30^{\circ} \mathrm{C}+65 \% \mathrm{RH}+\mathrm{Vac}$ ) on the Eudragit L100-55-based filaments. 
A
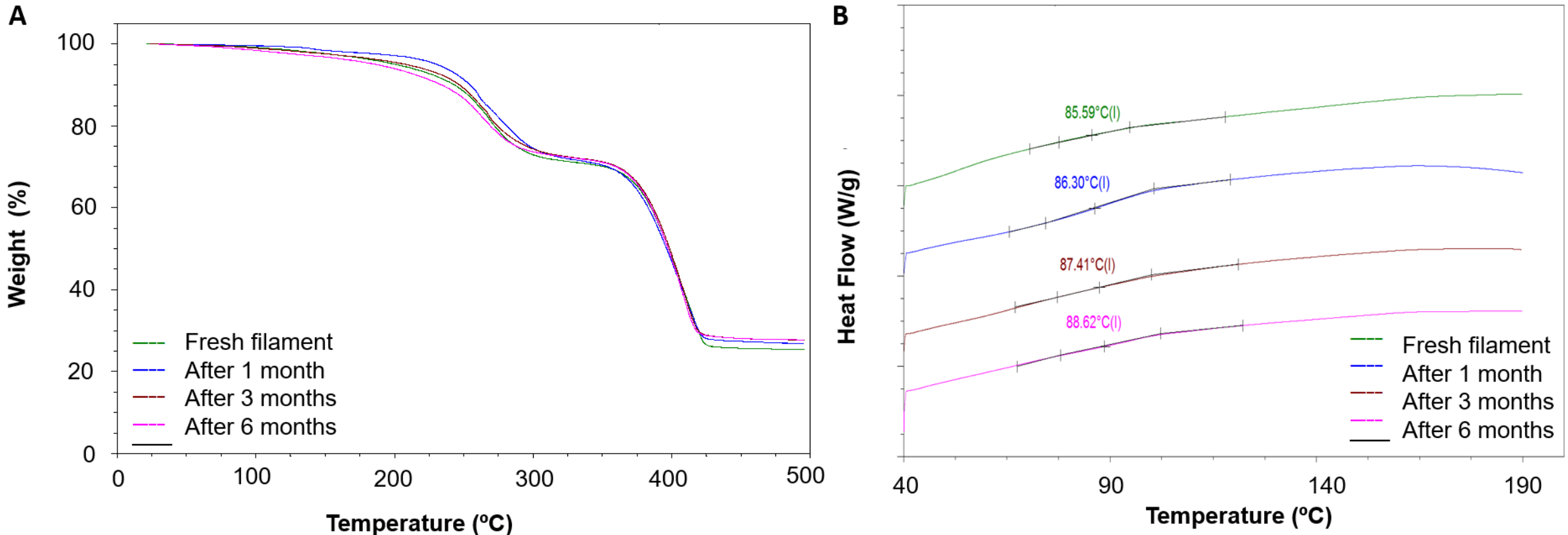

Fig. 4. Representative TGA (A) and DSC (B) thermographs for the impact of the storage conditions $\left(30{ }^{\circ} \mathrm{C}+65 \% \mathrm{RH}+\mathrm{Vac}\right)$ on the Eudragit S100-based filaments. 

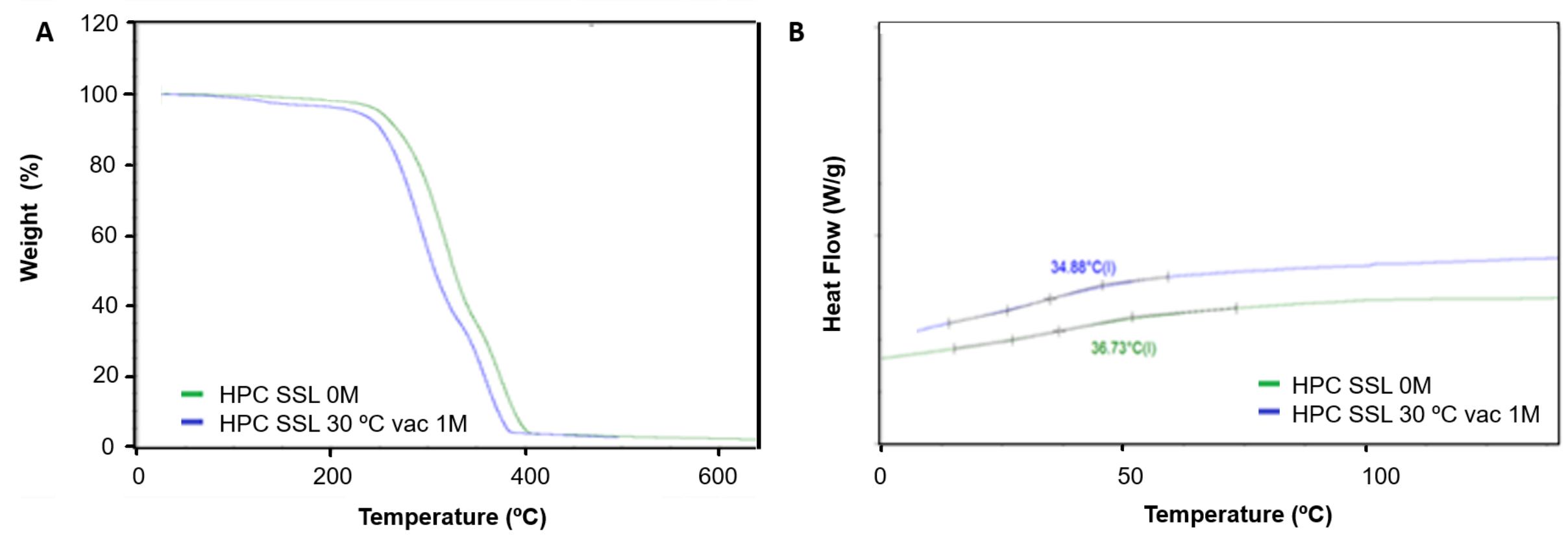

Fig. 5. TGA (A) and DSC (B) thermographs for the impact of the storage conditions on the HPC.SSL-based filaments. 


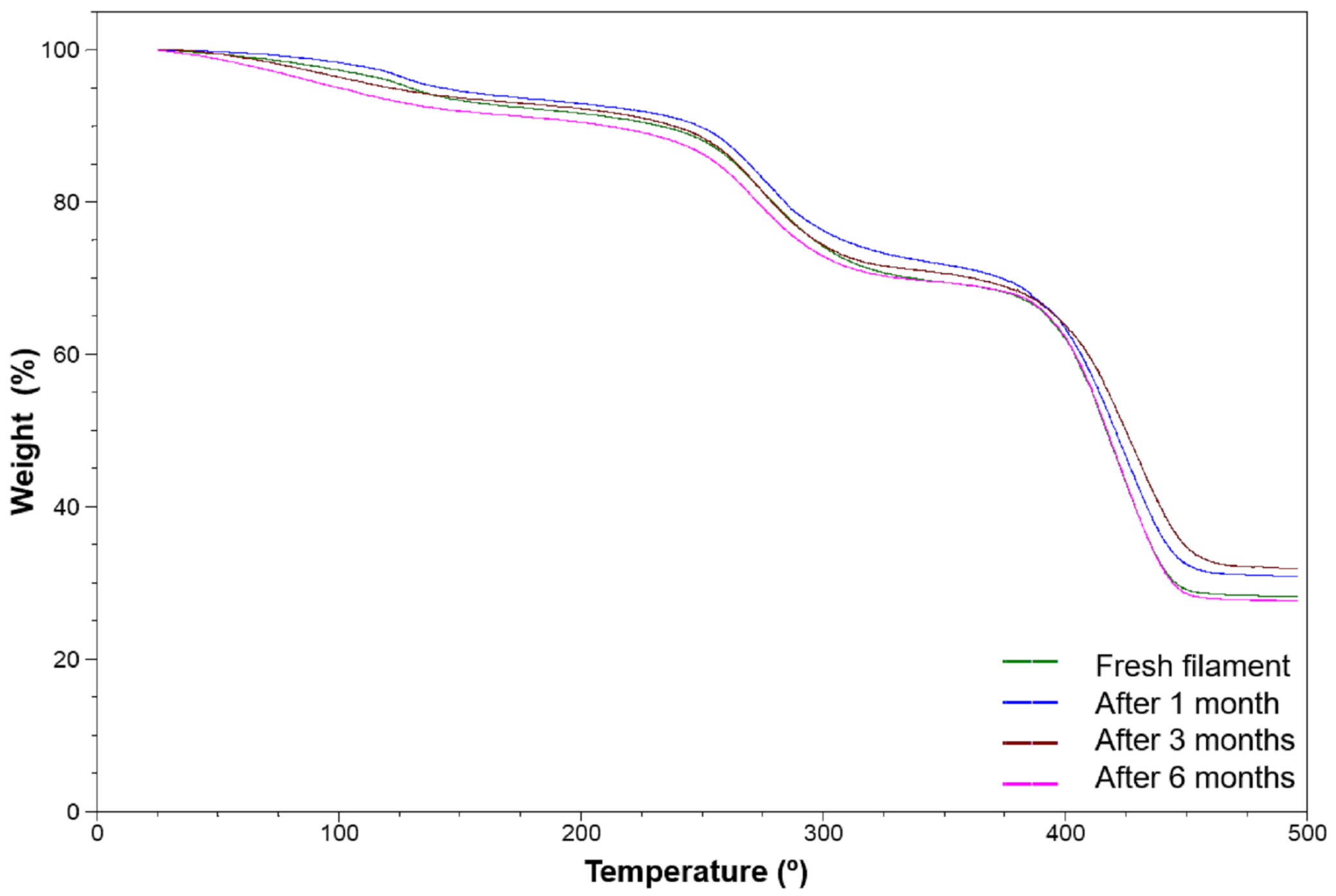

Fig. 6. TGA thermographs for the impact of the storage conditions $\left(5^{\circ} \mathrm{C}\right)$ on the PVP-based filaments. 

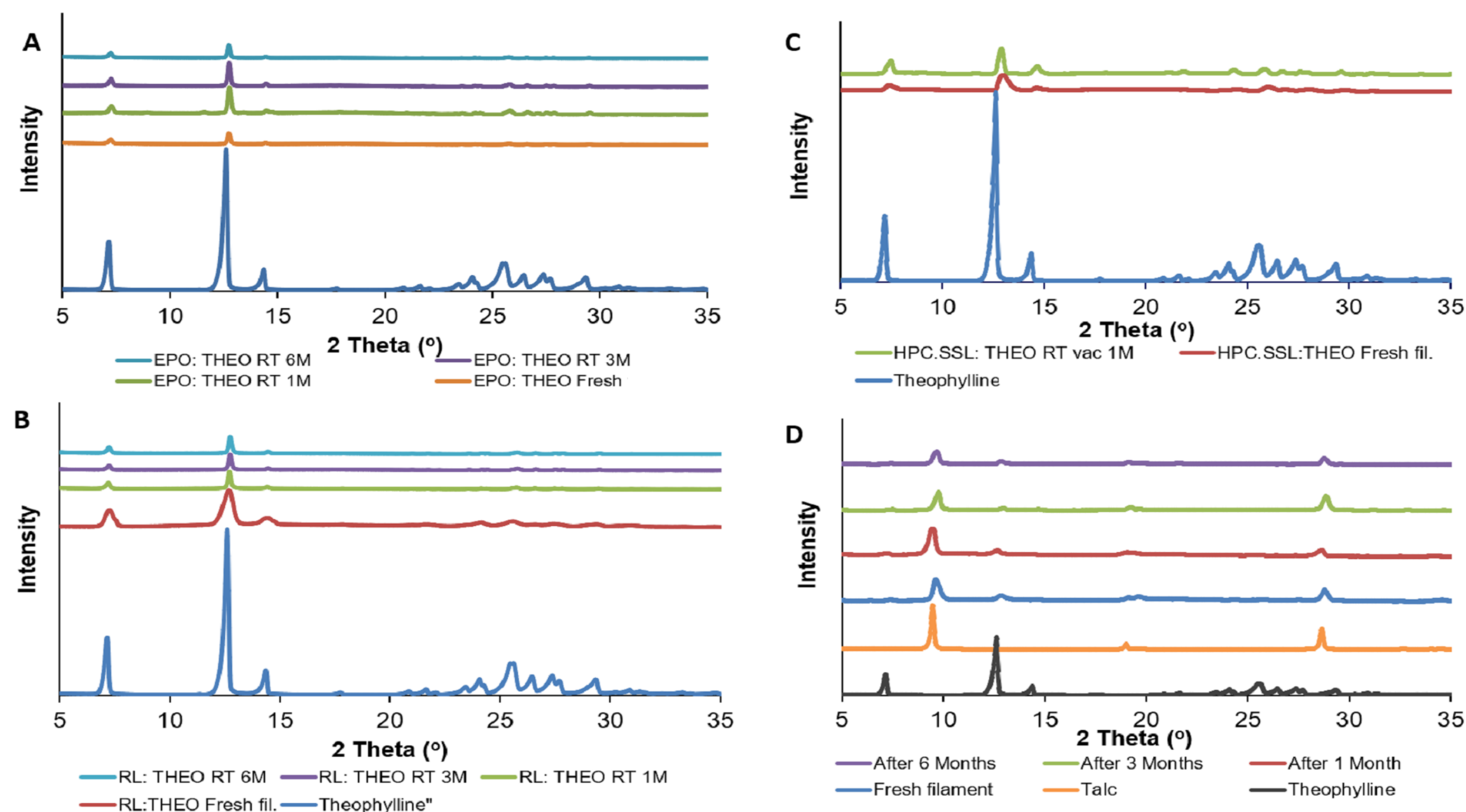

Fig. 7. XRPD data for the impact of the storage conditions on the Eudragit EPO (A), Eudragit RL (B), HPC.SSL (C) and PVP (D)-based drug loaded filament 


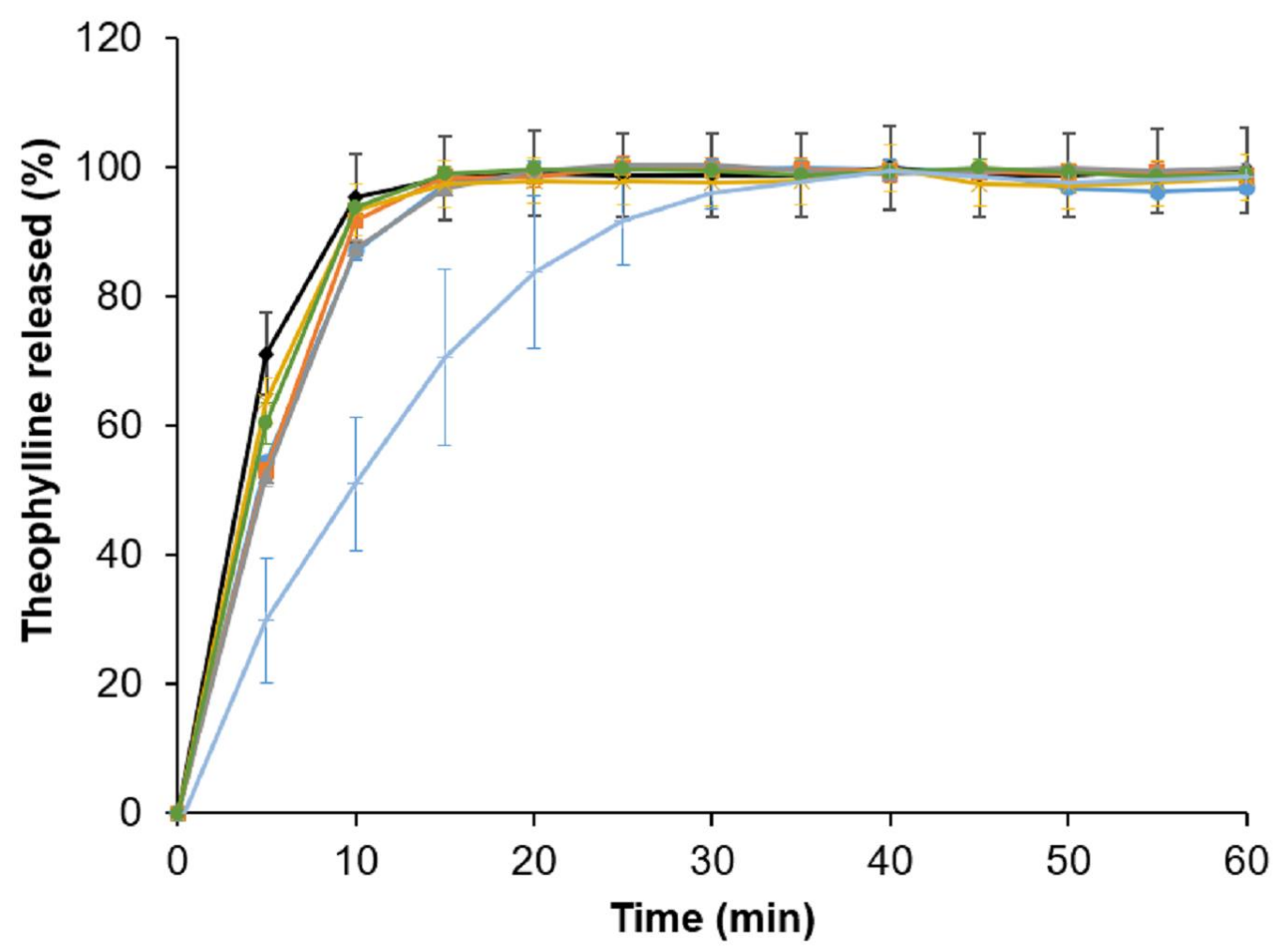

$\rightarrow-$ After 6 months + vacuum $\rightarrow$ After 3 months + vacuum

$\rightarrow$ After 1 months + vacuum $\_$After 6 months

$\rightarrow$ After 3 months $\rightarrow$ After 1 month

-Fresh filament

Fig. 8. The impact of storage at $5{ }^{\circ} \mathrm{C}$ on the in-vitro release profile of theophylline from the PVP-based product. 
A

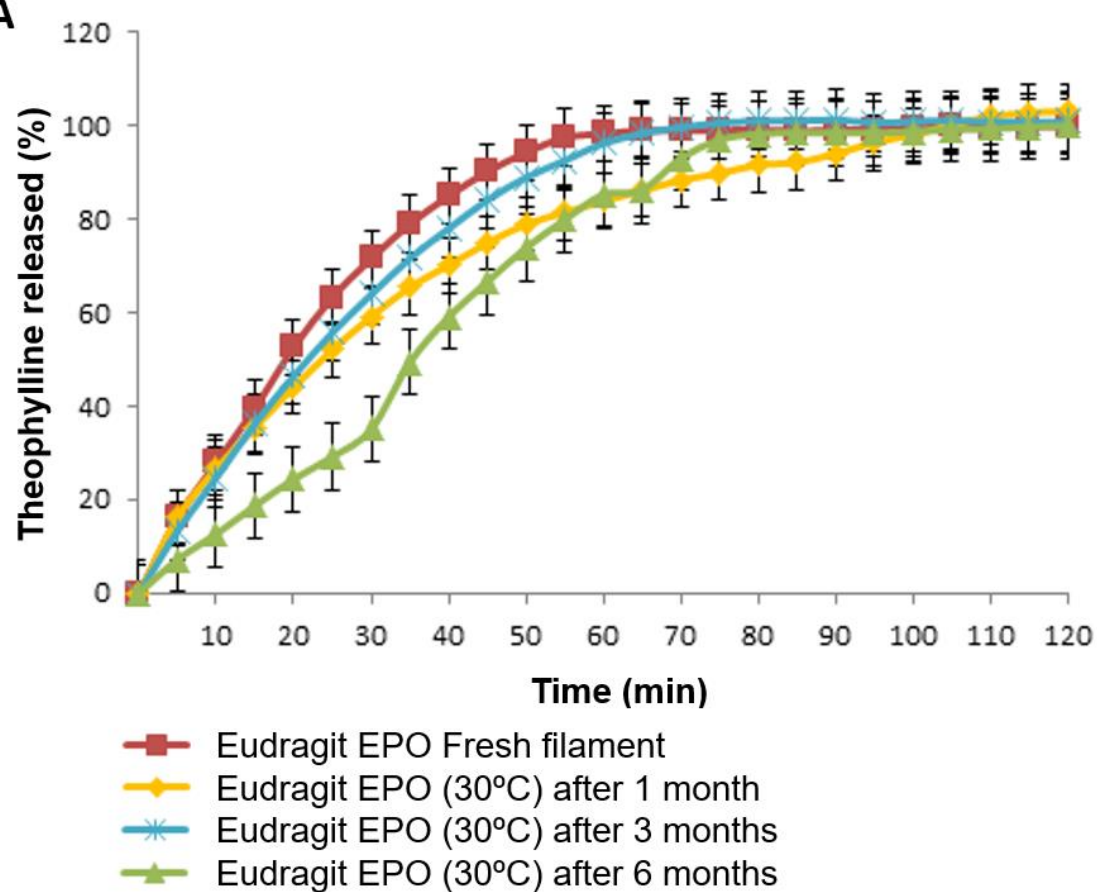

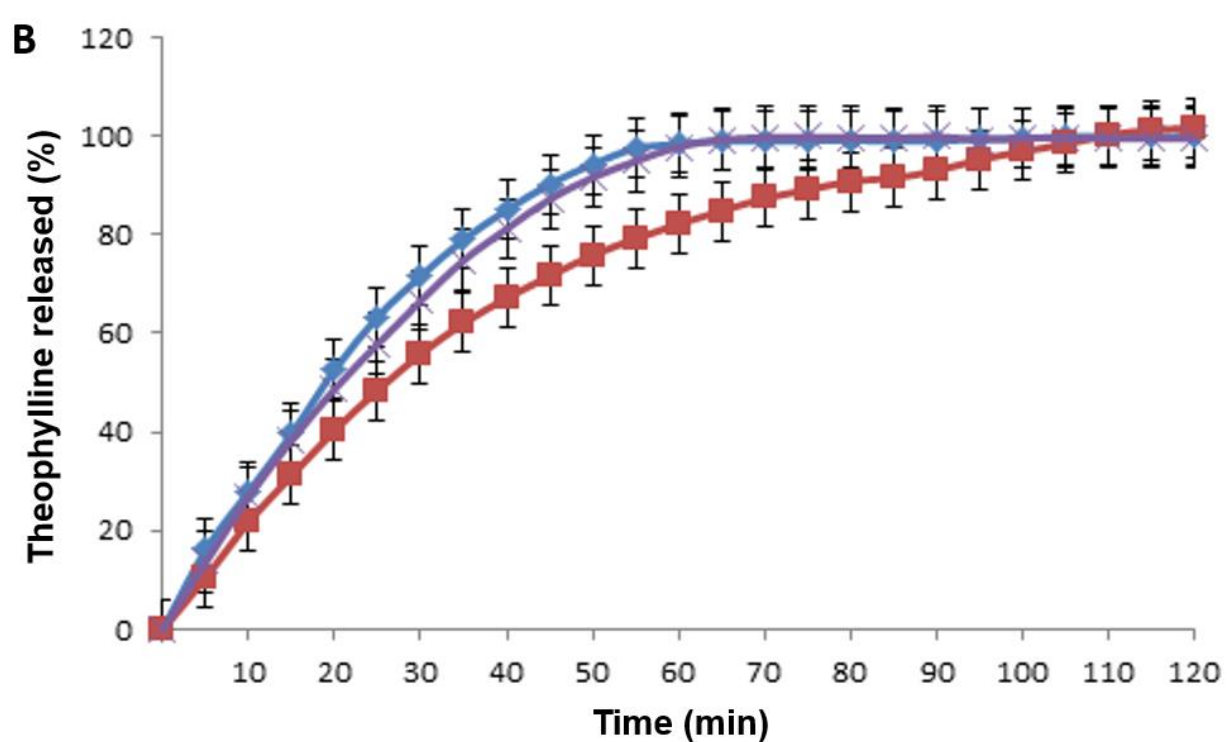

Time (min)

$\sim$ Eudragit EPO Fresh filament

- Eudragit EPO $\left(5^{\circ} \mathrm{C}\right)$ after 1 month

Eudragit EPO $\left(5^{\circ} \mathrm{C}\right)$ after 3 months

Fig. 9. The impact of the storage conditions on the in-vitro drug release profile of theophylline from the Eudragit EPO-based 3D printed tablets. 

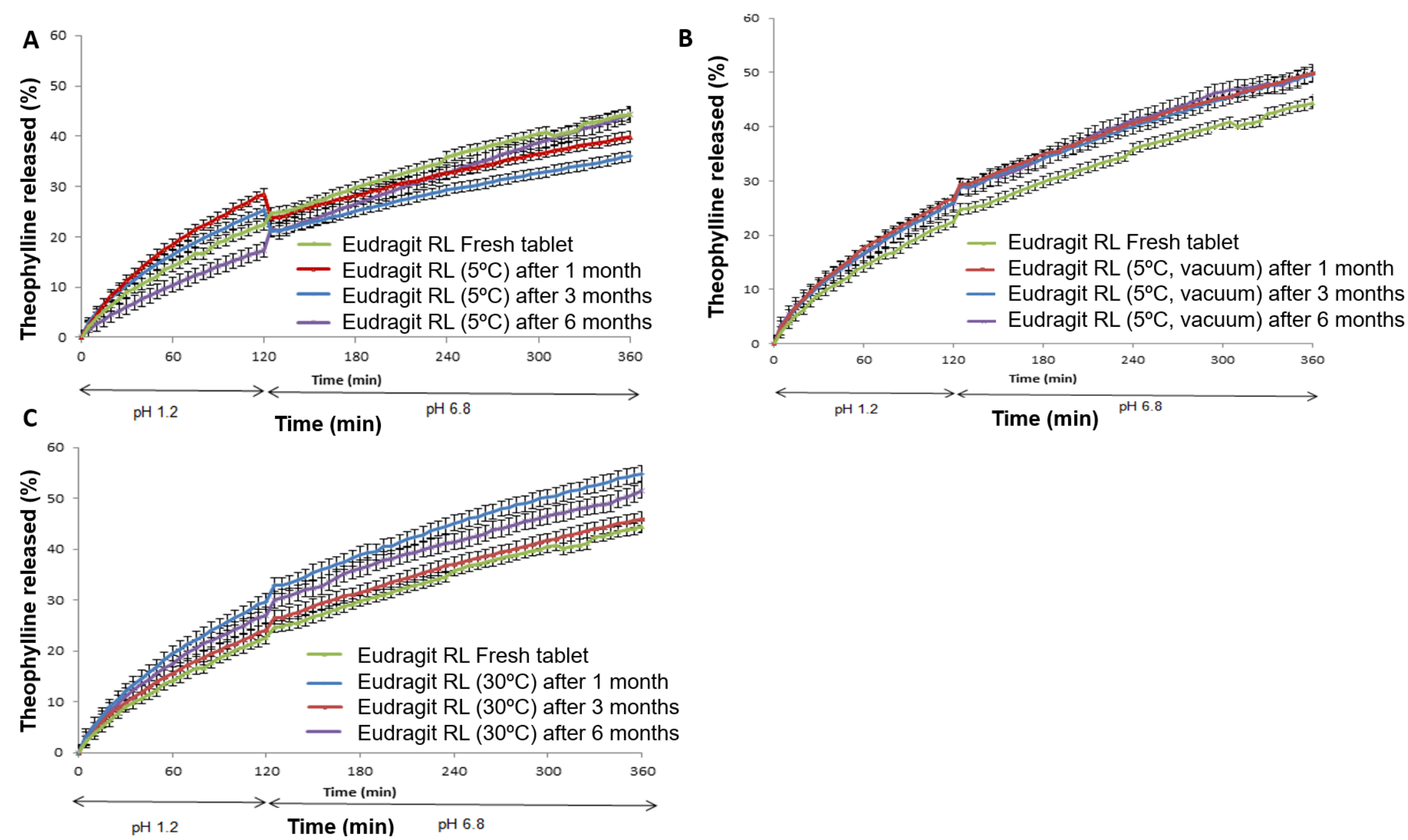

Fig. 10. The impact of the storage conditions on the in-vitro release profile of theophylline from the Eudragit RL-based 3D printed tablets. 
